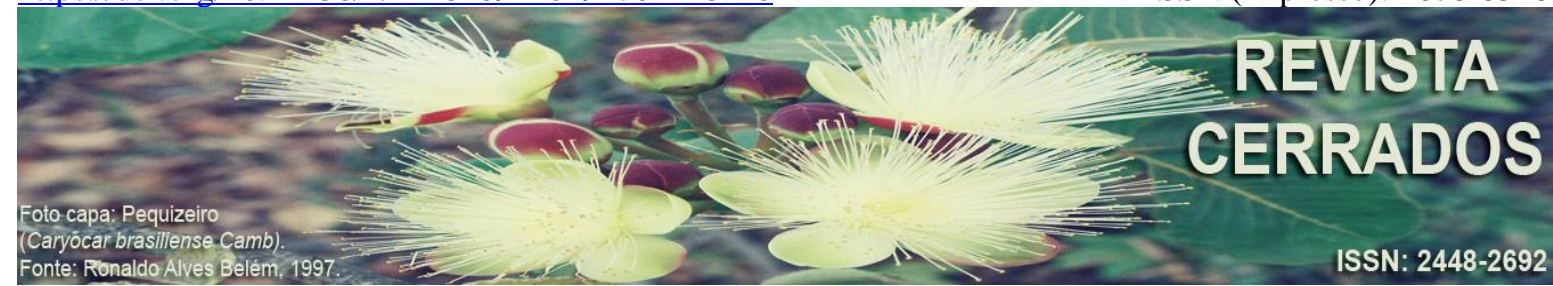

\title{
ANÁLISE DOS CENSOS AGROPECUÁRIOS BRASILEIROS DOS ANOS DE 2006 E 2017 PARA IDENTIFICAÇÃO DE CARACTERÍSTICAS DA POPULAÇÃO AGRÍCOLA
}

\author{
ANALYSIS OF BRAZILIAN AGRICULTURAL CENSUS OF THE \\ YEARS OF 2006 AND 2017 FOR IDENTIFICATION OF \\ CHARACTERISTICS OF THE AGRICULTURAL POPULATION
}

\section{ANÁLISIS DE LOS CENSOS AGROPECUARIOS BRASILEÑOS DE LOS AÑOS DE 2006 Y 2017 PARA IDENTIFICACIÓN DE CARACTERÍSTICAS DE LA POBLACIÓN AGRÍCOLA}

\author{
Sayonara Chagas da Silva Arrais iD 8 \\ Universidade Federal dos Vales do Jequitinhonha e Mucuri - UFVJM \\ E-mail: 〈sayochagas@hotmail.com>. \\ Bernat Viñolas Prat iD \\ Universidade Federal dos Vales do Jequitinhonha e Mucuri - UFVJM \\ E-mail: < bernatvinolasprat@gmail.com>. \\ Rosana Passos Cambraia iD \\ Universidade Federal dos Vales do Jequitinhonha e Mucuri - UFVJM \\ E-mail: < rosa.cambraia@ufvim.edu.br>
}

\section{RESUMO}

A agricultura é um setor da economia que está em constante desenvolvimento e vem contribuindo consideravelmente para o crescimento do PIB brasileiro. Devido a relevância desse segmento faz-se necessário conhecer o perfil dos trabalhadores rurais que estão contribuindo com esses resultados. Dessa forma, a pesquisa foi realizada com o objetivo de identificar as características da população agrícola brasileira, a partir de uma análise comparativa realizada com os dados disponíveis no Censo Agropecuário dos anos de 2006 e 2017. O estudo foi desenvolvido através da seleção de variáveis que apresentaram dados coletados e divulgados nos dois períodos de Censo, são elas: condição legal da terra, pessoa que dirige a propriedade, relação dos agricultores com financiamentos e divisão dos estabelecimentos por região. Como resultado constatou-se que em sua maioria os produtores são proprietários da terra em que trabalham e a maior parte dos estabelecimentos são dirigidos por homens. Os relacionamentos com instituições financeiras acontecem, geralmente, por meio de agências bancárias e tem a finalidade de custear as operações. A região Nordeste é a 
ARRAIS, S. C. S.; PRAT, B. V.; CAMBRAIA, R. P.;

Análise dos Censos Agropecuários Brasileiros dos Anos de 2006 e 2017 para Identificação de Características da População Agrícola

que abriga a maior quantidade de estabelecimentos rurais, com um número elevado de pequenas propriedades e o oposto acontece na região Centro-Oeste, que possui uma grande extensão de terras agricultáveis distribuída entre poucas propriedades rurais.

Palavras-chave: Produtor rural. Caracterização do produtor. Censo Agropecuário.

\begin{abstract}
Agriculture is a sector of the economy that is constantly developing and has been contributing considerably to the growth of Brazilian GDP. Due to the relevance of this segment, it is necessary to know the profile of rural workers who are contributing to these results. Thus, the research was conducted in order to identify the characteristics of the Brazilian agricultural population, from a comparative analysis performed with the data available in the Agricultural Census of 2006 and 2017. The study was developed through the selection of variables that presented data collected and disseminated during the two census periods, namely: legal status of the land, person who directs the property, relationship of farmers with financing, and division of establishments by region. As a result it was found that most producers own the land on which they work and most establishments are run by men. Relationships with financial institutions usually take place through bank branches and are intended to fund operations. The Northeast region is home to the largest number of rural establishments, with a large number of small properties and the opposite happens in the Midwest region, which has a large area of arable land distributed among few rural properties.
\end{abstract}

Keywords: Rural producer. Characterization of the producer. Agricultural Census.

\title{
RESUMEN
}

La agricultura es un sector de la economía que se desarrolla constantemente y ha contribuido considerablemente al crecimiento del PIB brasileño. Debido a la relevancia de este segmento, es necesario conocer el perfil de los trabajadores rurales que contribuyen a estos resultados. Por lo tanto, la investigación se realizó para identificar las características de la población agrícola brasileña, a partir de un análisis comparativo realizado con los datos disponibles en el Censo Agrícola de 2006 y 2017. El estudio se desarrolló a través de la selección de variables que presentó datos recopilados y difundidos durante los dos períodos del censo, a saber: estado legal de la tierra, persona que dirige la propiedad, relación de los agricultores con el financiamiento y división de establecimientos por región. Como resultado, se descubrió que la mayoría de los productores son dueños de la tierra en la que trabajan y que la mayoría de los establecimientos están a cargo de hombres. Las relaciones con las instituciones financieras generalmente tienen lugar a través de sucursales bancarias y están destinadas a financiar operaciones. La región del noreste es el hogar de la mayor cantidad de establecimientos rurales, con una gran cantidad de pequeñas propiedades y sucede lo contrario en la región del Medio Oeste, que tiene una gran área de tierra cultivable distribuida entre pocas propiedades rurales.

Palabras-clave: Productor rural. Caracterización del productor. Censo Agropecuario. 
ARRAIS, S. C. S.; PRAT, B. V.; CAMBRAIA, R. P.;

Análise dos Censos Agropecuários Brasileiros dos Anos de 2006 e 2017 para Identificação de Características da População Agrícola

\section{INTRODUÇÃO}

Entre os diversos setores da economia, a agricultura se destaca devido sua constante evolução, recebendo destaque desde as monoculturas até as diversificações de produção intensiva. Sua significativa participação no mercado contribui consideravelmente para o aumento do Produto Interno Bruto (PIB) e efetivamente para o crescimento da economia do país (RONCON, 2011).

Atualmente os agricultores se apresentam como os principais geradores de riquezas do país. Conforme dados divulgados pela Confederação da Agricultura e Pecuária do Brasil (CNA), a agricultura contribuiu com 23,5\% do PIB do país no ano de 2017 e os produtos brasileiros foram exportados para mais de 150 mercados ao redor do mundo. Entre o período de 1997 a 2017, a agricultura foi o setor que mais impactou a balança comercial e a geração de riqueza no país (CNA, 2018).

A produção agrícola nas propriedades rurais do Brasil é suficiente para alimentar quatro vezes a população de acordo com a CNA (2018). Conforme apresentado pelo Ministério da Agricultura, Pecuária e Abastecimento (MAPA) entre os diversos produtos agrícolas, destacam-se a mandioca, milho e a cana-de açúcar, como exemplo de produtos mais destinados ao mercado interno, e também a soja e o café que são mais voltados para atender o mercado externo. Ambos contribuem para elevar o crescimento do país. Na pecuária recebem destaque a produção de leite, de suínos e de carne bovina, esta última mais voltada para atender o mercado externo.

Diversos são os tipos de solo e clima que permeiam o território brasileiro. A tropicalização dos cultivos, devido aos climas diferenciados, pode ser considerada como fator favorável por permitir que as terras sejam aproveitadas em diversas condições climáticas. No entanto, existe também um antagonismo, pois grandes são as dificuldades enfrentadas pelos produtores rurais devido a essa variedade de solo e clima, a depender do produto que será produzido. Como forma de minimizar essas dificuldades, muitas vezes os produtores utilizam-se de recursos tecnológicos para realizarem processos como: correção de solo, irrigação, melhoria na adaptação de cultura, mecanização, entre outros.

O Estado deve incentivar os produtores rurais por meio de políticas públicas que visam dar suporte ao desenvolvimento de suas atividades produtivas. A exemplo da criação 
ARRAIS, S. C. S.; PRAT, B. V.; CAMBRAIA, R. P.;

Análise dos Censos Agropecuários Brasileiros dos Anos de 2006 e 2017 para Identificação de Características da População Agrícola

dos programas de financiamento ao setor produtivo das regiões Norte, Nordeste e CentroOeste, por meio da Lei $\mathrm{n}^{\mathrm{o}} 7.827 / 1989$, com o objetivo de acelerar o desenvolvimento de algumas regiões (BRASIL, 1989). Em 1996, por meio do Decreto Presidencial nº1.946 foi institucionalizado o Programa Nacional de Fortalecimento da Agricultura Familiar (PRONAF). O programa tem como objetivo fortalecer a agricultura familiar através do apoio técnico e financeiro, visando promover um desenvolvimento rural sustentável.

De acordo com Scheneider (2004), desde essa criação, o PRONAF tem se apresentado como a mais importante política pública do Governo Federal, voltada para apoiar os agricultores familiares. Com a criação do programa, houve um reconhecimento sobre a especificidade de uma nova categoria, a de agricultores familiares. Até este momento, a classe possuía diversas denominações, entre elas: pequenos produtores e agricultores de subsistência.

Diante da importância do setor agrícola para a economia brasileira, faz-se necessária uma análise para conhecer o perfil dessa classe dos produtores rurais, compreender como estão distribuídos nas regiões do país e assimilar sobre a sua transformação. O estudo foi elaborado com o objetivo de identificar características da população agrícola do Brasil, através de uma análise comparativa realizada entre os dados disponíveis no Censo Agropecuário $^{1}$ dos anos de 2006 e 2017, divulgados pelo Instituto Brasileiro de Geografia e Estatísticas (IBGE). A pesquisa versa sobre a identificação, tipificação e segmentação do produtor rural.

\section{METODOLOGIA}

Foram realizadas análises a partir dos dados divulgados pelo Censo Agropecuário 2006 e 2017 com a finalidade de obter informações que sirvam de subsídio para identificar características dos agricultores do Brasil. Para isso, foram selecionadas algumas variáveis que

\footnotetext{
1 O Censo Agropecuário investiga informações sobre os estabelecimentos agropecuários e as atividades agropecuárias neles desenvolvidas, abrangendo características do produtor e do estabelecimento, economia e emprego no meio rural, pecuária, lavoura e agroindústria. Tem como unidade de coleta toda unidade de produção dedicada, total ou parcialmente, a atividades agropecuárias, florestais ou aquícolas, subordinada a uma única administração (produtor ou administrador), independentemente de seu tamanho, de sua forma jurídica ou de sua localização, com o objetivo de produção para subsistência ou para venda. Foi realizado pela primeira vez em 1920, como parte integrante do Recenseamento Geral (IBGE, 2019. Disponível em: <https://www.ibge.gov.br/estatisticas/economicas/agricultura-e-pecuaria/21814-2017-censoagropecuario.html?=\&t=0-que-e $>$. 
ARRAIS, S. C. S.; PRAT, B. V.; CAMBRAIA, R. P.;

Análise dos Censos Agropecuários Brasileiros dos Anos de 2006 e 2017 para Identificação de Características da População Agrícola

estavam presentes nos dois Censos utilizados como fonte de dados para a pesquisam e que visam atender aos objetivos do estudo que é identificar características da população agrícola brasileira.

As variáveis selecionadas foram: condição legal da terra, pessoa que dirige a propriedade (sexo e grau de instrução), relação dos agricultores com financiamentos e divisão dos estabelecimentos por região. Com a seleção das variáveis, os dados foram tabulados e trabalhados em planilhas eletrônicas. Após todos os filtros, classificações e seleções necessárias, as informações foram confrontadas para melhor interpretação e análise dos resultados obtidos.

\section{CARACTERIZAÇÃO DA POPULAÇÃO AGRÍCOLA NO BRASIL}

\section{Condição legal das terras, segundo as variáveis selecionadas}

O primeiro quesito analisado tratou sobre a condição legal das terras. Foi traçada a forma de vínculo do produtor em relação à área do estabelecimento onde ele produz, segundo algumas variáveis selecionadas, que se justificam por se mostrarem adequadas para a análise dos dados realizadas no capítulo três.

Tais variáveis foram definidas em:

I) Terras próprias - propriedade do produtor;

II) Terras concedidas por órgão fundiário - aquela que não possui um título definitivo;

III) Terras arrendadas - propriedade de terceiros, explorada pelo produtor mediante pagamento previamente ajustado;

IV) Terras em parceria - propriedade de terceiros, explorada pelo produtor mediante pagamento de parte da produção;

V) Terras ocupadas - propriedade pertencente a terceiros, pela qual o produtor nada paga pelo uso e a explora mediante ocupação;

VI) Produtor sem área - aquele que obteve produção, mas não detém área específica própria e trabalha na área de um terceiro que permite a sua utilização. 
ARRAIS, S. C. S.; PRAT, B. V.; CAMBRAIA, R. P.;

Análise dos Censos Agropecuários Brasileiros dos Anos de 2006 e 2017 para Identificação de Características da População Agrícola

Além das variáveis mencionadas, no Censo de 2017 surgiu uma nova categoria denominada de comodato. Esse tipo de vínculo ocorre quando há o empréstimo da terra, sem ônus para o agricultor e este se obriga apenas a devolver o uso do espaço no tempo previamente acordado entre as partes.

Tabela 1 - Comparativo entre a condição legal do produtor rural brasileiro em relação à terra utilizada, de acordo com dados dos Censos Agropecuários de 2006 e 2017

\begin{tabular}{c|c|c}
\hline Condição do produtor em relação às terras & Censo 2006 & Censo 2017 \\
\hline Proprietário & $76 \%$ & $76 \%$ \\
\hline Concedido por órgão fundiário & $4 \%$ & $5 \%$ \\
\hline Arrendatário & $4 \%$ & $6 \%$ \\
\hline Parceiro & $3 \%$ & $3 \%$ \\
\hline Ocupante & $8 \%$ & $3 \%$ \\
\hline Produtor sem área & $5 \%$ & $1 \%$ \\
\hline Comodato & $0 \%$ & $6 \%$ \\
\hline TOTAL & $100 \%$ & $100 \%$ \\
\hline
\end{tabular}

Fonte: IBGE, Censo Agropecuário 2006 e 2017 - Adaptado pelos autores.

A tabela 1 evidencia a mudança que ocorreu na condição legas das terras, a partir das variáveis selecionadas para o estudo, confrontando os dados disponíveis no Censo de 2006 com o de 2017. Em geral os agricultores possuem a propriedade de suas terras e essa tendência pode ser observada em ambos os períodos. Por meio de uma análise realizada pelo Censo Agropecuário 2006, esse processo pode ser resultado de aquisição por meio de compra de particular, compra via crédito fundiário ou titulação via reforma agrária. No entanto, diversas são as maneiras de apropriação da terra, podendo compreender aquisição através de herança, usucapião, invasão ou até mesmo pela desapropriação.

A principal forma de acesso à terra, historicamente, foi a propriedade e sua importância tornou-se ainda maior nos últimos anos. O arrendamento teve sua participação aumentada, revelando que este mercado desempenha papel significativo como forma de acesso de trabalhadores rurais à terra. Destaca-se também o surgimento de expressivo número 
ARRAIS, S. C. S.; PRAT, B. V.; CAMBRAIA, R. P.;

Análise dos Censos Agropecuários Brasileiros dos Anos de 2006 e 2017 para Identificação de Características da População Agrícola

de agricultores que utilizam a terra sob comodato (6\%), bem como o declínio de produtores que não possuem terra, baixando de um percentual de $5 \%$ para apenas $1 \%$.

Segundo Medeiros (2005) o programa Banco da Terra teve grande contribuição para o acesso de trabalhadores às terras, sem a presença dos riscos envolvidos nas ocupações. O programa consistia em formar associações comunitárias para que os interessados pudessem escolher uma propriedade e negociarem com o proprietário a compra do bem. Nessa movimentação financeira, os trabalhadores recebiam o imóvel através da associação e o processo era intermediado por uma instituição financeira.

\section{Pessoa que dirige o estabelecimento, por sexo e nível de instrução}

As propriedades rurais, em geral, são administradas por homens, seguindo a tendência do patriarcalismo, o patriarca como autoridade central do grupo familiar (NASCIMENTO, 2017). O homem assume a função patriarcal dentro da base familiar e assume também o controle da propriedade. Brumer (2004) aponta que a sociedade paternalista atribui ao homem o papel de responsável pelo provimento da família. Dessa forma, as atividades geralmente desenvolvidas pelas mulheres nos estabelecimentos agropecuários, exigem qualidades que supostamente as mulheres possuem, tais como trabalhos manuais minuciosos. A tabela 2 expõe sobre o sexo do principal dirigente do estabelecimento rural nos períodos analisados.

Tabela 2 - Sexo do agricultor familiar que dirige o estabelecimento, de acordo com os dados dos Censos Agropecuários de 2006 e 2017

\begin{tabular}{c|c|c}
\hline Sexo & Censo 2006 & Censo 2017 \\
\hline Homem & $81 \%$ & $87 \%$ \\
\hline Mulher & $19 \%$ & $13 \%$ \\
\hline
\end{tabular}

Fonte: IBGE, Censo Agropecuário 2006 e 2017 - Adaptado pelos autores.

Os resultados encontrados corroboram com o estudo de Silva (2018), que traçou o perfil dos agricultores familiares na mesorregião do Agreste Paraibano. Ele verificou que $80,1 \%$ dos estabelecimentos apresentavam como dirigente do lar o produtor do sexo masculino e, por consequência, o restante $(19,9 \%)$ ficou sob a direção da mulher. No entanto, 
ARRAIS, S. C. S.; PRAT, B. V.; CAMBRAIA, R. P.;

Análise dos Censos Agropecuários Brasileiros dos Anos de 2006 e 2017 para Identificação de Características da População Agrícola

analisando os dados Censos de 2006 e 2017, percebe-se uma crescente participação da mulher como a pessoa responsável pelo estabelecimento rural.

Na pesquisa realizada por Brumer e Freire (1984), culturalmente na divisão de trabalho que se estabelece entre os sexos, cabe ao homem a exclusividade de desenvolver atividades que exigem maior força física e as mulheres ficam a cargo de executar serviços mais rotineiros, geralmente ligados à casa ou ao serviço agrícola, considerados de caráter mais leve. No entanto, essa definição de atividades leves e pesadas, conforme constatado por Paulilo (1987), está mais associada à posição que a mulher ocupa na hierarquia da família, do que propriamente às características do trabalho desenvolvido.

Quanto à faixa etária, fazendo um comparativo, os produtores rurais, em geral, possuem mais idade do que as empresas urbanas. Os jovens são minoria nesse segmento apenas 3,3\% dos produtores rurais têm menos de 25 anos. Esse dado pode alertar para a ocorrência do êxodo rural, uma vez que a permanência no campo se efetiva por pessoas mais idosas. Em relação à escolaridade, pouco mais de $10 \%$ deles cursaram ensino médio completo, sendo um público menos escolarizado do que os empreendedores urbanos (IBGE, 2006).

Em relação à distribuição do nível de instrução por sexo dos produtores, os dados obtidos revelam que, em geral, as mulheres responsáveis pelos estabelecimentos apresentam escolaridade mais baixa do que os homens. Conforme o Censo de 2006, para as categorias "não frequentou a escola" e "sem instrução, mas sabe ler e escrever", verificam-se $40 \%$ do total de informantes do sexo feminino e $33 \%$ do sexo masculino.

De acordo com os dados divulgados em 2017, esse cenário torna-se ainda mais expressivo para os dois sexos, com 50\% de mulheres que nunca frequentaram a escola, juntamente com as que sabem ler e escrever, porém não receberam instrução formal, contra $52 \%$ dos homens. No entanto, foi crescente também a proporção de agricultores que finalizaram seus estudos no ensino superior, variando de $3 \%$ para aproximadamente $6 \%$ dos informantes, bem como, conforme apresentado no quadro 1, foi apontada uma nova categoria que mostra uma faixa pequena de agricultores que concluíram mestrado e/ou doutorado. 
ARRAIS, S. C. S.; PRAT, B. V.; CAMBRAIA, R. P.;

Análise dos Censos Agropecuários Brasileiros dos Anos de 2006 e 2017 para Identificação de Características da População Agrícola

Quadro 1 - Pessoa que dirige o estabelecimento por sexo e nível de instrução, de acordo com os dados dos Censos Agropecuários de 2006 e 2017

\begin{tabular}{|c|c|c|c|c|}
\hline \multirow{2}{*}{ Nível de instrução } & \multicolumn{2}{c|}{ Censo 2006 } & \multicolumn{2}{c|}{ Censo 2017} \\
\cline { 2 - 5 } & Homem & Mulher & Homem & Mulher \\
\hline Não sabe ler e escrever/Não frequentou escola & $24 \%$ & $31 \%$ & $15,2 \%$ & $17,0 \%$ \\
\hline Sem instrução, mas sabe ler e escrever & $9 \%$ & $9 \%$ & $37,3 \%$ & $33,2 \%$ \\
\hline Alfabetizado já adulto & $5 \%$ & $6 \%$ & $1,4 \%$ & $1,9 \%$ \\
\hline E.F. Completo & & & & \\
\hline E.F. Incompleto & $9 \%$ & $7 \%$ & $25,5 \%$ & $26,0 \%$ \\
\hline E.M. Completo (técnico) & $43 \%$ & $37 \%$ & $*$ & $*$ \\
\hline E.M Completo (outro) & $1 \%$ & $1 \%$ & $1,6 \%$ & $1,2 \%$ \\
\hline Ensino Superior & $6 \%$ & $6 \%$ & $13,2 \%$ & $14,9 \%$ \\
\hline Mestrado ou doutorado & $3 \%$ & $3 \%$ & $5,6 \%$ & $5,7 \%$ \\
\hline
\end{tabular}

Fonte: IBGE, Censo Agropecuário 2006 e 2017 - Adaptado pelos autores.

(*) dados não informados ou não pontuados pelo Censo.

O nível de instrução da pessoa que dirige o estabelecimento tem forte relação com o recebimento de orientação técnica prestada pelas empresas de assistência técnica e extensão rural dos estados. Dos produtores com instrução igual ou inferior ao ensino fundamental incompleto, apenas $16,8 \%$ receberam assistência técnica, enquanto para os produtores com ensino médio completo este percentual sobe para $31,7 \%$. O sexo do produtor é determinante, para qualquer nível de instrução, pois os estabelecimentos dirigidos por mulheres parecem receber menos orientação técnica (IBGE, 2006).

O grau de instrução do agricultor também é fator relevante devido a facilidade de obtenção e processamento de informações, bem como a maneira correta para utilizá-las no trabalho desenvolvido. A gestão da propriedade torna-se mais segura e assertiva dependendo do grau de conhecimento intelectual do agricultor e também do nível de informatização disponível na propriedade.

Segundo Zanchet e Junior (2006) a baixa escolaridade do produtor acarreta na baixa organização do gerenciamento da propriedade, não existindo modelo de gestão nem mesmo a separação dos gastos entre os pessoais e os do negócio. Os autores constataram que 
ARRAIS, S. C. S.; PRAT, B. V.; CAMBRAIA, R. P.;

Análise dos Censos Agropecuários Brasileiros dos Anos de 2006 e 2017 para Identificação de Características da População Agrícola

o baixo grau de conhecimento dos produtores rurais relacionados aos conhecimentos básicos na área contábil-administrativa acarreta na inexistência de utilização de modelos gerenciais nos processos decisórios do negócio. As decisões tornam-se embasadas em métodos rudimentares de apontamentos e controles, com pouco ou nenhum conhecimento prévio na área contábil-administrativa.

As categorias de condição do produtor apresentam diferentes perfis instrucionais. Considerando a distribuição do percentual para o total de produtores do país, segundo os diferentes níveis de instrução, os proprietários e arrendatários formam um grupo com percentual mais elevado para os níveis de instrução acima do fundamental completo e mais elevados. Inversamente, os assentados sem titulação definitiva, parceiros, ocupantes e produtores sem-área, estão mais concentrados nas categorias de menor nível de instrução.

No país, a orientação técnica continua limitada. A área média do grupo assistido é de 228 hectares, enquanto a dos não assistidos é de 42 hectares. A orientação técnica de origem governamental atinge 43,0\% dos estabelecimentos assistidos e está mais voltada para os estabelecimentos menores, com área média de 64 hectares. Nas regiões Norte e Nordeste houve um avanço em relação à orientação técnica de origem governamental, o mesmo ocorrendo em Minas Gerais, Mato Grosso do Sul, Mato Grosso e Distrito Federal. Contrariamente ao ocorrido nestes Estados, houve redução de produtores que declararam receber orientação técnica governamental nos Estados do Rio de Janeiro, São Paulo, Paraná, Santa Catarina e Goiás (IBGE, 2006).

\section{Relação dos agricultores com financiamento}

Foi analisada a obtenção de financiamentos e empréstimos pelos estabelecimentos agropecuários em 2006 e 2017, junto a bancos (inclusive os provenientes de programas oficiais do governo, como o PRONAF); cooperativas de crédito; comerciantes de matériaprima; fornecedores de insumos e de equipamentos; empresa integradora; outras instituições financeiras; e junto a organizações não governamentais (ONG's), parentes ou amigos, bem como suas respectivas finalidades. Nesse quesito, não foram considerados os refinanciamentos, ou seja, financiamentos e empréstimos destinados a 'rolagem de dívidas' contraídas em anos anteriores.

Revista Cerrados, Montes Claros/MG, v.17, n. 2, p. 228-246, jul./dez.-2019. 
ARRAIS, S. C. S.; PRAT, B. V.; CAMBRAIA, R. P.;

Análise dos Censos Agropecuários Brasileiros dos Anos de 2006 e 2017 para Identificação de Características da População Agrícola

De todos os 5.175.489 estabelecimentos agropecuários pontuados no Censo de 2006, 4.254.808 (82\%) não obtiveram financiamento no ano-base. O principal motivo declarado foi a 'falta de necessidade' (51,9\%), seguido pelo 'medo de contrair dívidas' (20,7\%) e o empecilho da 'burocracia' $(8,4 \%)$. A figura 1 apresenta os principais motivos da não obtenção de financiamento.

Figura 1 - Motivo da não obtenção de financiamento pelos estabelecimentos agropecuários brasileiros, Brasil, 2006

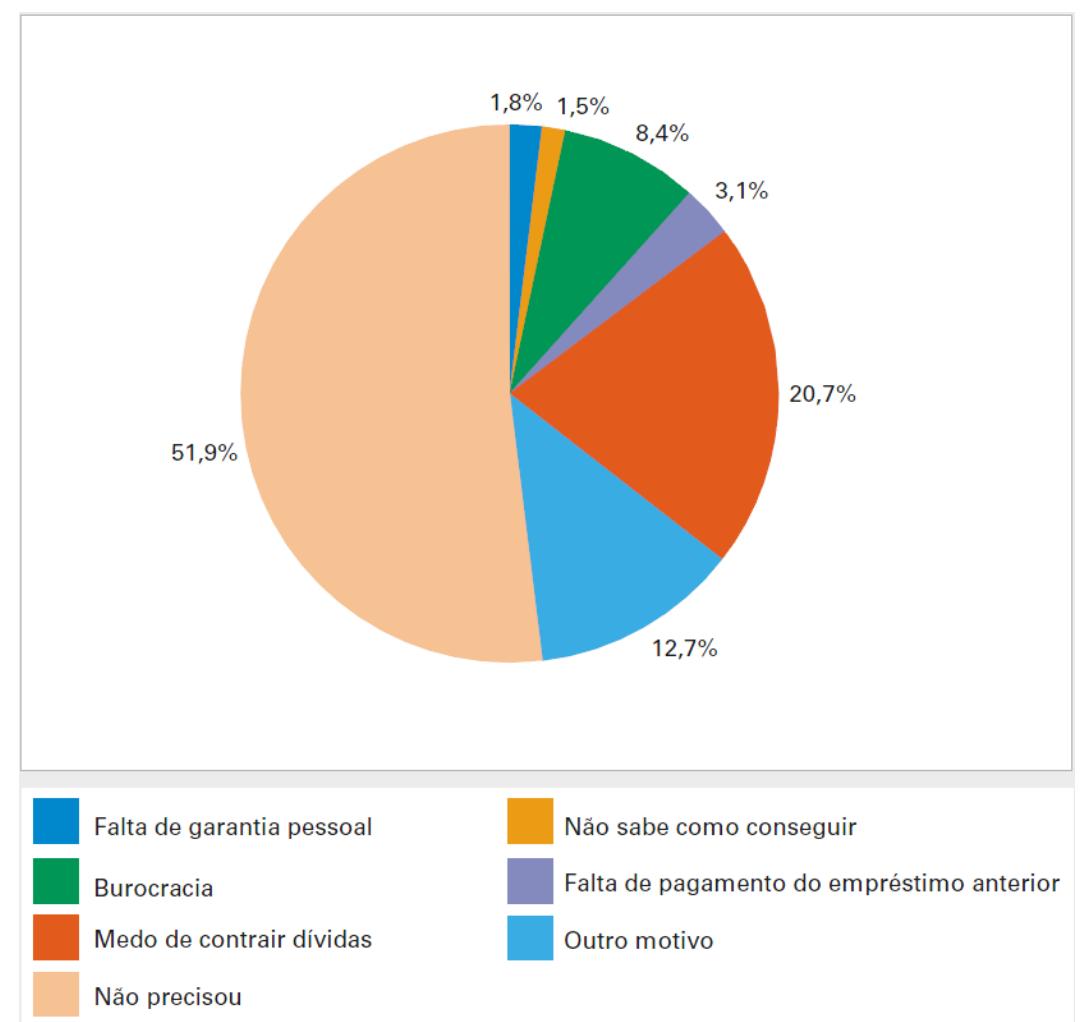

Fonte: IBGE, Censo Agropecuário 2006.

É importante ressaltar que ainda há uma desigualdade em relação ao acesso ao crédito entre grande e pequeno produtor, havendo, por exemplo, uma diferenciação nas taxas de juros praticadas nas operações, sendo taxas menores para grandes produtores e justificadas pelo maior montante da operação. A apresentação de garantias é outro fator que pode dificultar o acesso ao crédito, devido a problemas com a documentação de imóveis, por exemplo. 
ARRAIS, S. C. S.; PRAT, B. V.; CAMBRAIA, R. P.;

Análise dos Censos Agropecuários Brasileiros dos Anos de 2006 e 2017 para Identificação de Características da População Agrícola

Para os demais agricultores que sentiram a necessidade ou mesmo tiveram interesse em realizar empréstimos/financiamentos, foi analisada também qual a finalidade: investimento, custeio, comercialização e a manutenção do estabelecimento. $\mathrm{O}$ gráfico 1 mostra a distribuição dessa opção, pela obtenção do empréstimo junto as instituições financeiras, através da quantidade de estabelecimentos.

Gráfico 1 - Finalidade da obtenção de empréstimo pelos agricultores rurais, conforme os Censos Agropecuários de 2006 e 2017.

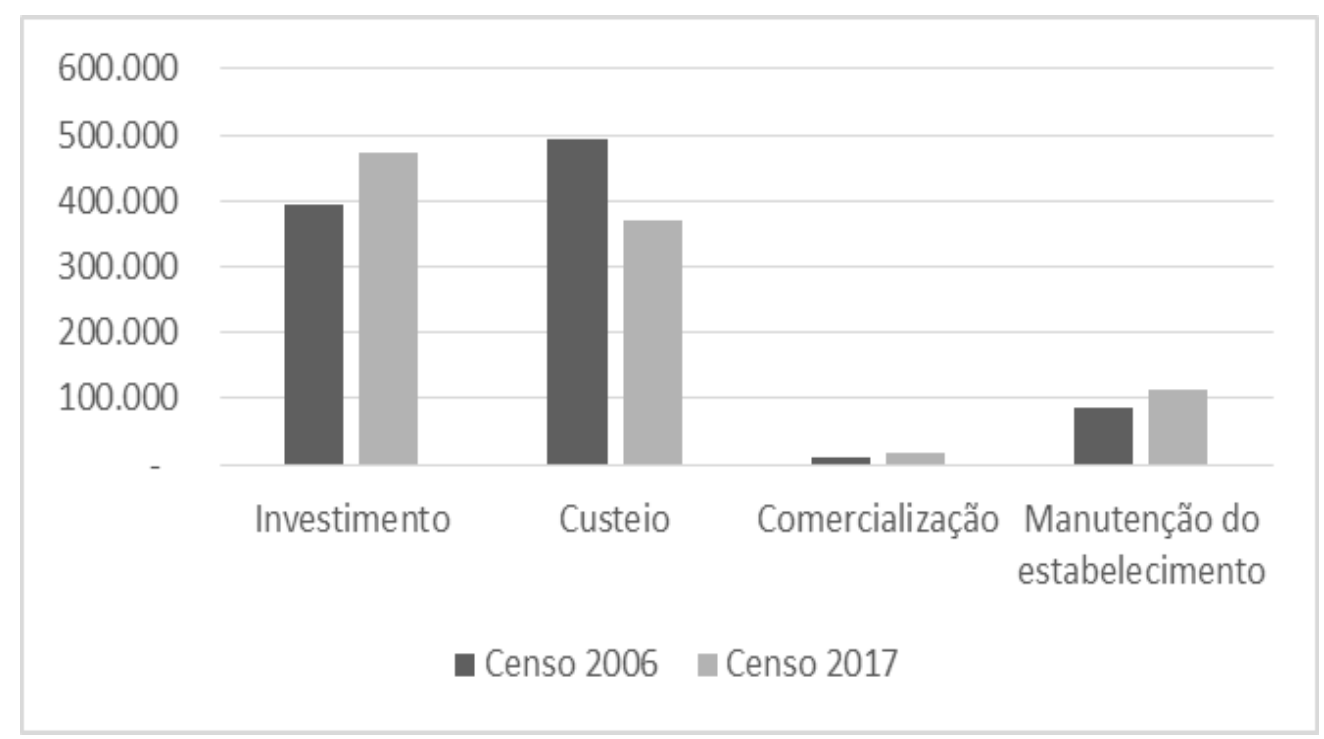

Fonte: IBGE, Censo Agropecuário 2006 e 2017 - Adaptado pelos autores.

Até o ano de 2006, a maior parte dos empréstimos realizados era para financiar o custeio agrícola, ou seja, as despesas normais do ciclo produtivo. Esse resultado confirma o estudo realizado por Assunção \& Chein (2007), quando analisaram as condições de crédito no Brasil e identificaram uma tendência para aquisição de crédito, nos anos 2000 e 2004, com a finalidade de custear as despesas da produção, tais como: aquisição de insumos e material necessário para a produção, por exemplo.

O Censo de 2017 revelou uma tendência de mudança no mercado, apresentando a finalidade 'investimento' como a intenção predominante dos agricultores. Essa mudança pode estar relacionada com o aumento do grau de instrução de alguns produtores, que estão concluindo o ensino superior e ingressando em cursos de pós-graduação e se especializando em seus próprios negócios, visando a expansão de seus mercados. 
ARRAIS, S. C. S.; PRAT, B. V.; CAMBRAIA, R. P.;

Análise dos Censos Agropecuários Brasileiros dos Anos de 2006 e 2017 para Identificação de Características da População Agrícola

Gráfico 2 - Agente financeiro responsável pela concessão de empréstimo rural segundo o Censo Agropecuário de 2017

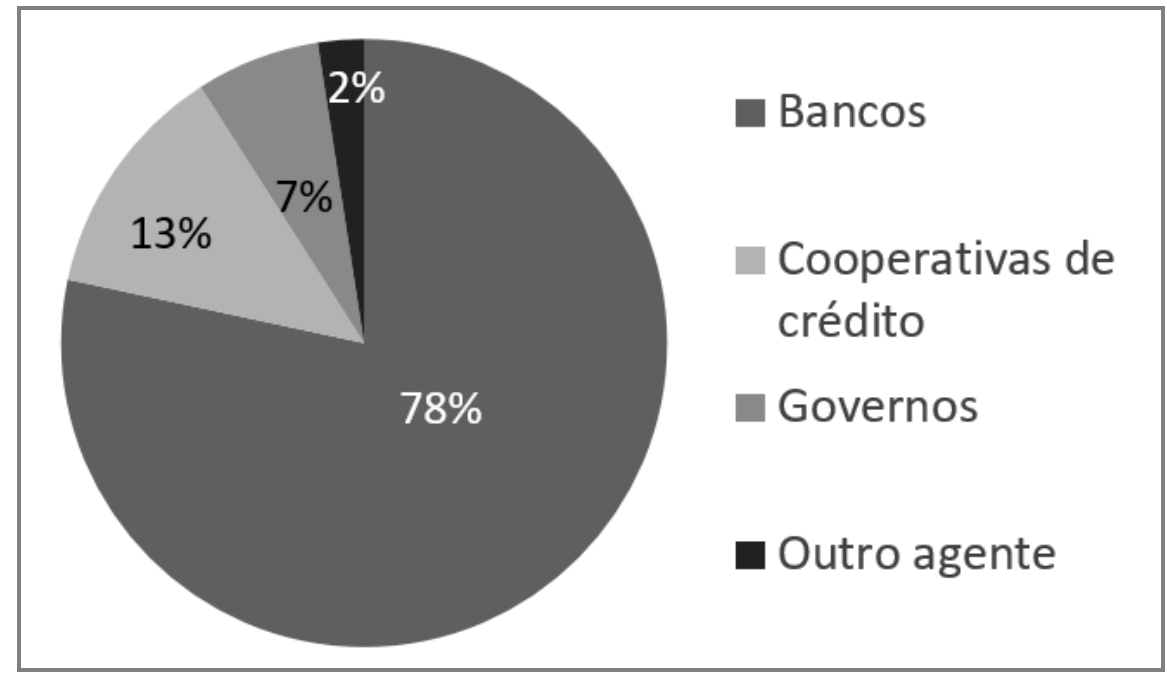

Fonte: IBGE, Censo Agropecuário 2017 - Adaptado pelos autores.

O gráfico 2 apresenta a distribuição pela procura da instituição responsável por intermediar as operações financeiras. Quanto ao agente financeiro que está envolvido nessas negociações, os bancos representam $78 \%$ desses estabelecimentos (gráfico 2). Esse dado mostra a intensificação da inclusão social que ocorreu, principalmente ligada às políticas públicas que fizeram com que vários pequenos produtores tivessem acesso ao crédito pela primeira vez (BATISTA E NEDER, 2014). As cooperativas de crédito apresentam-se como a segunda instituição financeira mais procurada pelos produtores rurais que buscam crédito para aplicarem nos negócios.

Diante dos dados disponíveis na literatura e das condições que foram apresentadas pelos produtores em relação ao conservadorismo e até mesmo pela necessidade em expandir os negócios, foram criadas pelos autores desse TCM novas categorias para análise levando em consideração o perfil de cada produtor rural sobre crédito. As novas categorias podem ser divididas em quatro:

a) Agricultores recessivos - aqueles que trabalham com o mínimo de recursos financeiros e que não possuem acesso à educação (marginalizados);

b) Agricultores tradicionais - aqueles que possuem o mínimo de escolaridade e buscam crédito para investir em atividades convencionais; 
ARRAIS, S. C. S.; PRAT, B. V.; CAMBRAIA, R. P.;

Análise dos Censos Agropecuários Brasileiros dos Anos de 2006 e 2017 para Identificação de Características da População Agrícola

c) Agricultores empreendedores - aqueles que não necessariamente possuem um bom nível de escolaridade e buscam crédito para inovar na propriedade visando o crescimento do negócio rural;

d) Agricultores informatizados - aqueles que possuem um bom nível de escolaridade, conhecimento sobre gestão do negócio e buscam cada vez mais o crescimento do empreendimento rural.

\section{Distribuição dos estabelecimentos por regiões}

Realizando a análise por região, o Nordeste foi a que apresentou maior quantidade de estabelecimentos rurais em ambas as análises, perfazendo o total de 47\%, seguida pela região Sul, com 20\% em 2006. No ano de 2017 os percentuais baixaram para 46\% na região Nordeste e para $17 \%$ na região Sul, conforme apresentado no gráfico 3. A região Centro-Oeste foi a que apresentou o menor quantitativo de estabelecimentos rurais nos dois períodos analisados.

Gráfico 3 - Percentual de estabelecimentos rurais distribuídos nas regiões do país, conforme os Censos Agropecuários de 2006 e 2017

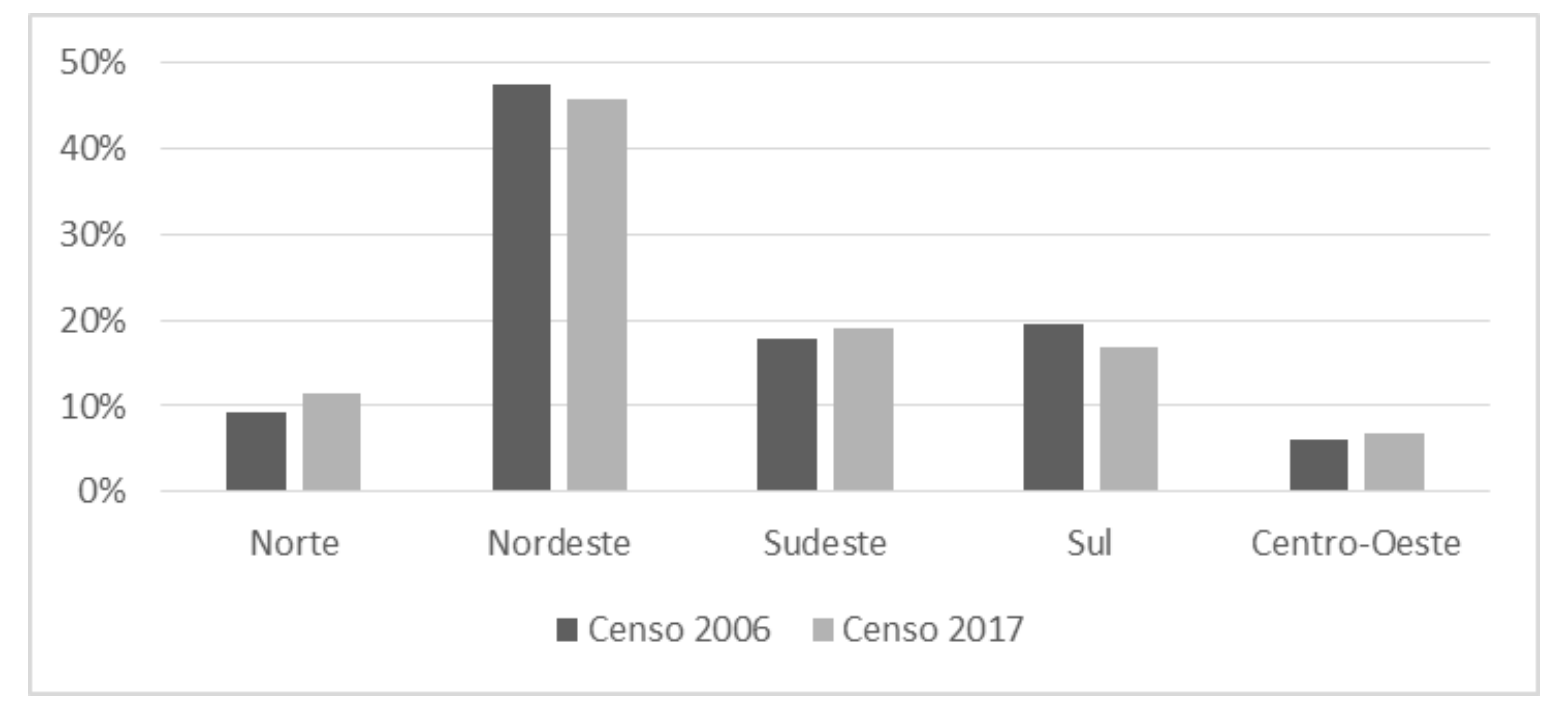

Fonte: IBGE, Censo Agropecuário 2006 e 2017 - Adaptado pelos autores.

No entanto, em se tratando de extensão territorial rural, a região Centro-Oeste liderou a lista, com o total de $31 \%$ (2006) e 32\% (2017), seguida pela região Nordeste (23\% e 
ARRAIS, S. C. S.; PRAT, B. V.; CAMBRAIA, R. P.;

Análise dos Censos Agropecuários Brasileiros dos Anos de 2006 e 2017 para Identificação de Características da População Agrícola

$20 \%$ respectivamente), ficando em terceiro lugar a região Norte que apresentou um aumento no período analisando, passando de $17 \%$ para $19 \%$ a extensão de área rural. Por último ficou a região Sul, conforme apresenta o gráfico 4 abaixo.

Gráfico 4 - Percentual de hectare por região referente aos estabelecimentos rurais, conforme os Censos Agropecuários de 2006 e 2017

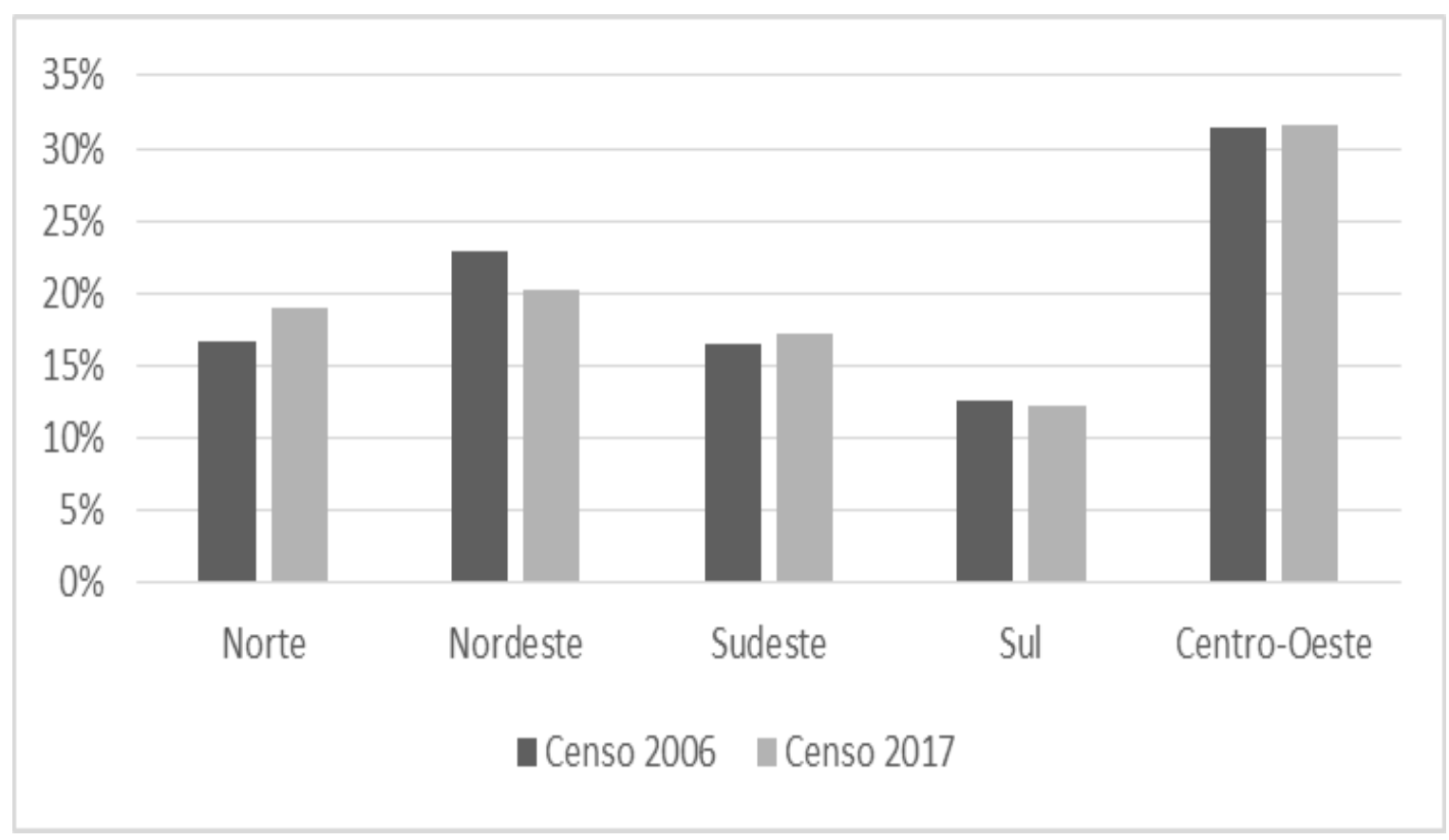

Fonte: IBGE, Censo Agropecuário 2017 - Adaptado pelos autores.

Em relação ao tamanho das propriedades, $90 \%$ das mesmas possuem área inferior aos 100 hectares, indicando o predomínio das pequenas propriedades no Brasil. Quanto à distribuição geográfica, constatou-se a predominância da região Nordeste seguida pela região Sul como as que possuem o maior número de propriedades rurais. O Centro-Oeste é a região com o menor número absoluto de propriedades (cerca de 6\% a 7\%), devido especialmente à maior concentração de grandes propriedades nessa região, trata-se de região monocultora voltada para agricultura predominantemente comercial.

$\mathrm{Na}$ análise realizada nos Censos de 2006 e 2017 percebeu-se que a área ocupada por estabelecimentos agropecuários cresceu 16,5 milhões de hectares no período analisado. No entanto, ainda assim ocorreu uma redução de $2 \%$ em relação ao número de propriedades, verificando-se uma maior concentração de propriedades, com 5,07 milhões de unidades em 2017 contra 5,17 milhões em 2006 (IBGE, 2017).

Revista Cerrados, Montes Claros/MG, v.17, n. 2, p. 228-246, jul./dez.-2019. 
ARRAIS, S. C. S.; PRAT, B. V.; CAMBRAIA, R. P.;

Análise dos Censos Agropecuários Brasileiros dos Anos de 2006 e 2017 para Identificação de Características da População Agrícola

\section{CONSIDERAÇÕES FINAIS}

Devido a amplitude e diversidade da agricultura, o homem do campo exerce papel fundamental na economia do país. A partir do esforço dos agricultores, independentes do tamanho de porte, muitos empregos são gerados diretamente no campo e, como em uma reação de cadeia, em sistemas de negócios e indústria.

Embora tenha-se constatado uma diminuição de 1,5 milhão no total de trabalhadores em propriedades rurais, o perfil traçado do produtor rural brasileiro aponta que em sua maioria são proprietários da terra onde trabalham. Os estabelecimentos são dirigidos por homens, quase em sua totalidade, e ambos os sexos apresentam baixo nível de escolaridade, apontando para parte expressiva que nunca frequentou a escola.

Por muito tempo os agricultores evitaram o relacionamento com instituições financeiras, alegando a falta de necessidade e também o medo de contrair dívida. No entanto, após os incentivos do governo com políticas de créditos que estimulam as linhas para a agricultura, essa relação com financiamentos foi se tornando mais estreita. Em sua maioria, as operações de crédito rural ocorrem com a finalidade de custeio e investimento e os principais agentes financiadores são os bancos.

Os estabelecimentos rurais são mais numerosos na região Nordeste, porém é lá também que estão concentradas a maioria das pequenas propriedades, tornando-se o oposto da região Centro-Oeste, caracterizada por possuir pequenas quantidades de propriedades com muitos hectares, os latifúndios.

Entre as cinco regiões, apenas a Nordeste apresentou uma queda em relação a área dos estabelecimentos agropecuários. Uma justificativa para o ocorrido pode ser encontrada considerando um período de cinco anos de secas na região que acarretou em um processo de desertificação de parte do espaço.

Muito ainda será exigido dos produtores rurais, para maximização de produção e aproveitamento da terra com a finalidade de geração de alimentos para a movimentação da economia. Dessa forma, faz-se necessária cada vez mais a valorização dessa classe, a realização de mais investimentos voltados para área rural e mais pesquisas acerca de sua importância e contribuição para o país. 
ARRAIS, S. C. S.; PRAT, B. V.; CAMBRAIA, R. P.;

Análise dos Censos Agropecuários Brasileiros dos Anos de 2006 e 2017 para Identificação de Características da População Agrícola

\section{REFERÊNCIAS}

ASSUNÇÃO, J; CHEIN, F. Condições de crédito no Brasil rural. Revista de Economia e Sociologia Rural, Brasília, v. 45, n. 2, p. 371-372, 2007.

BATISTA, H.R; NEDER, H.D. Efeitos do PRONAF sobre a pobreza rural do Brasil (20012009). Revista de Economia e Sociologia Rural, Brasília, v. 52, supl. 1, p. 150, 2014.

BANCO CENTRAL DO BRASIL. Crédito Rural. Disponível em:

$<$ https://www3.bcb.gov.br/mcr/manual/09021771806f488d.htm?fullName=2\%20-

\%20Cr\%C3\%A9ditos\%20de\%20Custeio>. Acesso em: 10 ago. 2018.

BRASIL. Lei n. 7.827, de 27 de setembro de 1989. Regulamente o art. 159, inciso I, alínea c, da Constituição Federal, institui o Fundo Constitucional de Financiamento do Norte - FNO, o Fundo Constitucional de Financiamento do Nordeste - FNE e o Fundo Constitucional de Financiamento do Centro-Oeste - FCO, e dá outras providências. Diário Oficial da República Federativa do Brasil, Brasília, DF, 27 de setembro de 1989. Disponível em:

<http://www.planalto.gov.br/Ccivil_03, leis/L7827.htm>. Acesso em: 06 fev. 2018.

BRASIL. Ministério da Agricultura, Pecuária e Abastecimento - MAPA. Safra de grãos deve alcançar 300 milhões toneladas em dez anos. DF: Brasília. Disponível em:

$<$ http://www.agricultura.gov.br/noticias/safra-de-graos-deve-alcancar-300-milhoes-ton-degraos-em-dez-anos-indica-estudo>. Acesso em: 05 ago. 2018.

BRUMER, A. Gênero e Agricultura: A situação da mulher na agricultura do Rio Grande do Sul. Universidade Federal do Rio Grande do Sul, p. 205-227, 2004. Disponível em:< http://www.scielo.br/pdf/ref/v12n1/21699.pdf >. Acesso em: 01 de maio 2018.

BRUMER, A; FREIRE, N.M.S. O trabalho da mulher na pequena produção agrícola. Revista do Instituto de Filosofia e Ciências Humanas da Universidade Federal do Rio Grande do Sul, ano XI/XI, p. 302-322, 1984.

CONFEDERAÇÃO NACIONAL DA AGRICULTURA - CNA. Agricultor, a mais nobre das profissões. Disponível em: <http://www.cnabrasil.org.br/artigos/agricultor-mais-nobredas-profissoes>. Acesso em: 05 ago. 2018.

INSTITUTO BRASILEIRO DE GEOGRAFIA E ESTATÍTICA - IBGE. Censo Agropecuário 2006. Disponível em:

<http://biblioteca.ibge.gov.br/visualizacao/periodicos/51/agro_2006.pdf>. Acesso em: 28 nov. 2017.

INSTITUTO BRASILEIRO DE GEOGRAFIA E ESTATÍSTICA - IBGE. Censo Agropecuário 2017. Disponível em:

< https://censoagro2017.ibge.gov.br/templates/censo_agro/resultadosagro/index.html>. Acesso em: 15 ago. 2018. 
ARRAIS, S. C. S.; PRAT, B. V.; CAMBRAIA, R. P.;

Análise dos Censos Agropecuários Brasileiros dos Anos de 2006 e 2017 para Identificação de Características da População Agrícola

MEDEIROS, L.S. "Sem terra”, “Assentados”, “Agricultores Familiares”: considerações sobre os conflitos sociais e as formas de organização dos trabalhadores rurais brasileiros. In: Una nueva ruralidad em America Latina? Colección de CLACSO. Libronauta Argentina S.A. 2005, p. 108-133.

NASCIMENTO, V.F. Patriarcado rural: Permanência e alterações da ordem patriarcal no meio rural. IV Encontro Nacional e X Fórum Estado, Capital Trabalho. Universidade Federal de Sergipe (UFS). 2017.

PAULILO, M.I.S. O peso do trabalho leve. Ciências Hoje, Rio de Janeiro: SBPC, v. 5, n. 28, p. 64-70, jan-fev. 1987.

RONCON, N. A importância do setor agrícola para a economia brasileira. Fundação Educacional do Município de Assis - FEMA/IMESA. Assis, 2011, p. 69.

SCHNEIDER, S; MATTEI, L; CAZELLA, A.A. Histórico, caracterização e dinâmica recente do Pronaf. In: . (Org.) Políticas públicas e participação social no Brasil rural. Porto Alegre: Ed. UFRGS, 2004, p. 21-50.

SILVA, A.B.A.D. Perfil da agricultura familiar do Agreste Paraibano: uma tipificação contextualizada. João Pessoa, 2018. Acesso em: 01 de maio 2019.

ZANCHET, A; JUNIOR, S.C.F. Perfil contábil-administrativo dos produtores rurais e a demanda por informações contábeis. Ciências Sociais Aplicadas em Revista, v. 6, n. 11, 2006.

\section{Autores}

Sayonara Chagas da Silva Arrais - Possui Graduação em Ciências Contábeis pela Universidade Federal do Ceará (UFC) e Mestrado em Saúde, Sociedade e Ambiente pela Universidade Federal dos Vales do Jequitinhonha e Mucuri (UFVJM). Atualmente é analista Bancária do Banco do Nordeste do Brasil S/A.

Bernat Viñolas Prat - Possuiu Graduação em Engenheria Civil, Mestrado em Engenharia da Construção e Doutorado em Engenharia da Construçao, todos cursados pela Universitat Politècnica de Catalunya (UPC/Espanha). Atualmente é pesquisador e professor no mestrado profissional Sociedade, Sáude e Meio Ambiente (UFVJM).

Rosana Passos Cambraia - Possuiu Graduação em Zootecnia pela Universidade Federal de Viçosa (UFV), Mestrado em Psicobiologia pela Universidade de São Paulo (USP) e Doutorado em Psicobiologia pela Universidade de São Paulo (USP/RIB. PRETO). Atualmente é Docente nos programas de pós graduação Stricto sensu, modalidade mestrado profissional Interdisciplinar em Saúde, Sociedade \& Ambiente (FCBS/UFVJM) e na modalidade acadêmica Interdisciplinar em Estudos Rurais (FIH/UFVJM). 
ARRAIS, S. C. S.; PRAT, B. V.; CAMBRAIA, R. P.;

Análise dos Censos Agropecuários Brasileiros dos Anos de 2006 e 2017 para Identificação de Características da População Agrícola

Artigo recebido em: 15 de junho de 2019.

Artigo aceito em: 28 de outubro de 2019.

Artigo publicado em: 21 de novembro de 2019. 